
del Patrimonio Arqueológico. Algunas propuestas de actuación
en Andalucía

Ignacio Rodríguez Temiño

Dirección General de Bienes Culturales Junta de Andalucía

\section{Consideraciones previas}

El expolio, especialmente en el sentido amplio que el legislador ha dado a este término, como pérdida, destrucción o impedimento para cumplir la función a que están Ilamados los bienes culturales (art. 4 Ley 16/1985, de 25 de junio, del Patrimonio Histórico Español [en adelante LPHE], corroborado por la Sentencia del Tribunal Constitucional 17/|99|), constituye sin lugar a dudas una de las externalidades más graves y preocupantes entre las que actúan sobre el patrimonio histórico de carácter arqueológico, hasta el punto de constituir la lucha contra el mismo un campo de concurrencia competencial entre todas las administraciones públicas, según razona la citada sentencia en sus fundamentos jurídicos $3^{\circ}$ y $7^{\circ}$.

Sin embargo, a pesar de este reconocimiento, la lucha contra el expolio arqueológico no se ha materializado en una política lo suficientemente desarrollada por las administraciones culturales como para paliar sus estragos. Carencia que afecta no sólo al Estado español, sino a todo el ámbito europeo. Si bien es notoriamente conocido que esta lacra se ceba especialmente en los países del entorno mediterráneo, donde han surgido civilizaciones con gran esplendor en sus manifestaciones artísticas y artesanales.

Las causas de la falta de control en muchas de las actividades que podrían denominarse expoliadoras son variadas, pero en general, aunque con notables variaciones entre países ricos y pobres, se reducen a la nefasta combinación de una legislación poco adecuada y la carencia de recursos humanos, medios económicos y técnicos suficientes para llevar a cabo una labor de salvaguarda eficaz. A esta mezcla debe añadirse el estado embrionario de las políticas preventivas de difusión y promoción, que podrían encauzar una protección activa apoyada en el aumento del nivel educativo de la población de muchos de estos países. Esto incidiría positivamente en la raíz del problema aunque fuese a medio y largo plazo. En resumidas cuentas, por múltiples razones el panorama dista mucho de ser halagüeño.
Antes de proseguir, me parece necesario hacer ciertas consideraciones en torno al expolio del patrimonio arqueológico con objeto de centrar el tema de esta exposición. Posteriormente pasaré al análisis de la situación actual en la comunidad autónoma de Andalucía, por ser de donde cuento con mayor cantidad de información.

En primer lugar, es preciso aclarar que, en aras de la concisión, restrinjo la amplitud antes mencionada del término expolio a la de realización de remociones de tierra clandestinas, normalmente asociadas al uso de detectores de metal, en busca de objetos antiguos destinados al coleccionismo particular, como reza el título de esta exposición.

Este tema resulta ser uno de los aspectos de la protección del patrimonio arqueológico menos considerados, a pesar de haberse convertido en una de las amenazas más extendidas debido a la popularización del uso de estas máquinas, y a los pingües beneficios que lleva aparejado la venta ilegal de piezas arqueológicas.

En segundo lugar, y sin ánimo de entrar ahora en disquisiciones más profundas sobre la naturaleza del patrimonio arqueológico, definido en el artículo 40 LPHE como aquéllos bienes muebles e inmuebles de carácter histórico susceptibles de ser estudiados con metodología arqueológica, conviene hacer hincapié en que se trata de unos bienes especialmente vulnerables al daño y la destrucción, en razón de unas características inherentes a su propia esencia.

Destaca entre estas características la imprevisibilidad de su aparición. Obviamente, los restos arqueológicos suelen aparecer en conjuntos denominados yacimientos (que normalmente corresponde con antiguas áreas de actividad humana), pero no exclusivamente en ellos. A lo largo de la historia, por razones de toda índole, se han ocultado o depositado objetos o estructuras en lugares alejados de las áreas de hábitat, que actualmente forman cierto tipo de yacimientos arqueológicos de carácter 


\author{
Lo prohibido por el legislador andaluz es la actividad (esto es, el uso de un detector de \\ metales), sin que tenga especial significación, a este respecto, la existencia del dolo \\ específico de buscar restos arqueológicos.
}

puntual, cuya localización es virtualmente imposible de predecir, encontrándose esparcidos por amplias partes del territorio.

Igualmente importa decir que el monto total de yacimientos arqueológicos es desconocido, pero aunque no sea posible determinar ahora mismo cuál es su número, sí sabemos que es finito. Los catálogos e inventarios de yacimientos arqueológicos suponen un registro de los conocidos y, en modo alguno, la totalidad del patrimonio arqueológico existente en una zona.

Unidos a estos argumentos está el de la imposibilidad de restitución del daño producido a los restos arqueológicos. El carácter de esta irreversibilidad viene derivado de la necesaria contextualización de los restos arqueológicos para que pueda permitirse su estudio. Por ejemplo, la huella dejada por un hogar prehistórico antes de ser excavada contiene un caudal informativo que, tras removerse de su situación original, se ha perdido, convirtiéndose lo que antes era una estructura arqueológica en un montón de cenizas y tierra con escaso o nulo valor arqueológico. Obviamente, esta información no se devuelve esparciendo de nuevo las cenizas por el suelo. Lo que no se haya registrado en ese momento es imposible de recuperar. Ni siquiera otra estructura similar contendrá la misma documentación; cada entidad arqueológica es única e irrepetible.

Tomando en cuenta estas consideraciones, la legislación sobre patrimonio histórico ha sido especialmente cuidadosa en lo tocante al patrimonio arqueológico. Así, ciñéndome exclusivamente a la LPHE, el legislador ha establecido una serie de cautelas para asegurar la protección de estos bienes, que van desde la consideración de su carácter demanial (art. 44 LPHE) hasta la declaración ope legis como bienes de interés cultural, de un determinado elenco de bienes (cuevas y abrigos con arte rupestre) en el artículo 40.2 LPHE, pasando por someter a un régimen de previa autorización las actuaciones destinadas a intervenir en él (art. 42.I LPHE), extremo éste que ha sido ampliamente desarrollado por la legisla- ción autonómica, de manera que se restringen las condiciones de quiénes pueden solicitar este tipo de autorización con objeto de asegurar la rigurosidad científica de la actividad. Esta cautela atiende al crucial papel que juega la metodología arqueológica en la propia definición jurídica de este patrimonio especial, y que, a la postre, será esa rigurosidad científica una de las garantías de que el resultado final de la intervención arqueológica sea el enriquecimiento del conocimiento histórico.

En tercer lugar, debe indicarse que se desconoce la magnitud del grado de afección que el expolio ha perpetrado al patrimonio arqueológico, como ya señalara L. Caballero (1982: 29) hace más de quince años, sin que desde entonces hasta ahora haya cambiado mucho la situación a este respecto.

La opacidad de estos datos surge obviamente de encontrarnos ante una actividad clandestina, carente de todo tipo de control y, por tanto, sin medios precisos para cualquier cuantificación. Sin embargo, habría algunas cifras que sí deberían ser conocidas, aunque fuese de forma aproximada, por las administraciones concernidas. Por ejemplo, se ignora, siquiera con una aproximación fiable, el número de yacimientos, no ya "peinados" con detectores de metal, sino objeto de amplios movimientos de tierra con la intención de exhumar estructuras arqueológicas -especialmente tumbas- en las que expoliar los ajuares. Normalmente es a través de inspecciones directas, tras una denuncia, a tal o cual yacimiento; de la visita a un mercadillo o una colección particular; o más comúnmente, con la presentación ante los medios de comunicación de una colección de objetos arqueológicos requisada por las autoridades judiciales o policiales, como puede entreverse la dimensión del daño causado por este fenómeno, siempre en la creencia de que con estos casos sólo asoma la punta del iceberg. Pero poco más que conjeturas se ponen encima de la mesa al hablar sobre esto.

Sin embargo, algo más podría haberse hecho y debería hacerse, en especial cuando en los últimos 
tiempos la investigación arqueológica ha conocido un crecimiento exponencial de las actividades de prospección directa del territorio, realizadas ahora de forma sistemática y detenida, y con una estructuración de la información en fichas prediseñadas para normalizar la recogida de datos. En muchas de esas fichas no existe la más mínima referencia a si se aprecian señales de haber sido expoliado el yacimiento, algo fácil de observar en la mayoría de las ocasiones (Iniesta Sanmartín, 1996); en otras, como en las de los inventarios y catálogos al uso en las administraciones, apenas se deja espacio para indicar que ha sido expoliado, pero sin más precisiones en cuanto al área afectada o al volumen de los desmontes, despreciándose así una importantísima fuente de conocimiento de primera mano. En fin, de haberse tomado en cuenta estos extremos con suficiente consideración, ahora tendríamos elementos de juicio suficientes para su cuantificación, al menos en las grandes áreas geográficas afectadas por el expolio, algo que sólo conocemos de forma intuitiva o en muestras posiblemente no suficientemente representativas.

En otro orden de cosas pero también relacionado con la cuantificación del fenómeno de la expoliación de yacimientos arqueológicos, tampoco se tiene idea aproximada del número de detectoristas en cada comunidad autónoma, aunque se sabe de la existencia de asociaciones locales de aficionados a esta labor, como la asociación Karmo radicada en Carmona (Sevilla) o Corduba-Al Andalus de Córdoba, y de federaciones de éstas a escala regional y estatal, caso de la Asociación Española de Detectoristas Aficionados, que además publica (o al menos lo hacía) un boletín denominado El Buscador. Nunca -que yo sepa- se han usado estas vías para poner en conocimiento de los afiliados a las mismas las obligaciones legales que conlleva tal práctica con respecto a los bienes integrantes del patrimonio arqueológico, por cuanto que el código ético del detectorista es claramente insuficiente para estos fines, por cuanto que reduce éstos a los yacimientos y las zonas arqueológicas declarados bien de interés cultural!

En cuarto lugar, la desproporción entre la magnitud de la tarea a emprender y la escasez de medios dedicados a ella ha provocado una suerte de tradicional inhibición en las administraciones concernidas, y entre los expertos, que suplen la inactividad con el lamento (lo que L. Caballero denomina en el trabajo citado "pesimismo generalizado en los ambientes arqueológicos") para, seguidamente, dejar de lado el problema por considerarlo insoluble, prefiriendo otros campos más "rentables" en términos de compensación de esfuerzos.

Por su puesto, existen razones suficientes para justificar el papel de Jeremías desempeñado habitualmente por los arqueólogos. Pero también es cierto que, a fuerza de orillar el problema, paradójicamente se le ha dedicado poca atención a pesar de su importancia2; que, debido a esta marginación, quienes tienen alguna experiencia en este campo nunca han considerado re- levante transmitirla, o no han encontrado los foros idóneos para hacerlo; que se ha clamado por leyes represoras de las conductas expoliadoras, pero ha faltado reivindicar de la administración campañas educativas de difusión sobre el papel de la arqueología en la sociedad, más allá del aprecio por los objetos antiguos, como se ha hecho en otros países y reclama la normativa internacional.

La lentitud de respuesta de la administración al expolio y lo menguado de sus resultados a primera vista, también ha provocado la desesperación entre quienes tienen conocimiento, de forma más o menos directa, de las piezas traficadas ilegalmente en los últimos años; desesperación que procuran combatir abogando por otras medidas más posibilistas para recuperar esas piezas, fundamentalmente la compra (Fernández Gómez, 1996, por ejemplo). Para mayor abundancia en la justificación de esta postura, se suele hacer referencia a que es la actitud mantenida por muchos países del norte de Europa en relación con los detectores de metal y los hallazgos producidos por ellos.

Sin ánimo de entrar en otro tipo de consideraciones de tipo deontológicas, sí requieren ciertos comentarios las alusiones al modo de operar en otros países, ya que quienes aportan este tipo de paralelos parecen ignorar las diferencias en los sistemas jurídicos que rigen en unos y otros.

En el Reino Unido, por ejemplo, la búsqueda de metales antiguos no está prohibida (sólo se precisa el permiso de la propiedad de los terrenos), aunque exista una conciencia clara en muchos medios profesionales y sociales sobre el daño que cometen. No obstante, en Inglaterra al menos, English Heritage (199|) ha distribuido unas by-laws reguladoras de esta actividad, estableciendo la conveniencia, ampliamente seguida por las casas comercializadoras de estos artefactos, de incluir un libreto en el que se recuerda la prohibición de prospectar en yacimientos protegidos a los efectos previstos en la Ancient Monuments and Archaeological Areas Act de 1979, lo que refleja el comentado código ético de los detectoristas en el Estado español aunque aquí los condicionantes jurídicos son absolutamente diferentes, como veremos más adelante. También se recuerda la idoneidad de ofrecer al museo local más cercano aquellos hallazgos más sobresalientes, cuya adquisición, en su caso, se efectúa mediante compra.

Para comprender este modo de actuar conviene repasar la legislación sobre patrimonio histórico del Reino Unido en materia de hallazgos casuales de bienes arqueológicos. Las reglas generales que rigen en los casos de hallazgos casuales en terrenos públicos y privados en ese país tienen una excepción importante: cuando lo hallado está compuesto por metales preciosos. En este caso, el hallazgo pasa a la Corona. Es la conocida como Ley del Treasure trove, de origen medieval pero aún en vigor. Su nacimiento se debía a la necesidad de sufragar gastos del gobierno, pero la situación hoy día es bastante 
distinta, ya que los derechos de la Corona sobre los hallazgos de tesoros desde los últimos cien años han sido el medio para proteger piezas de interés para la comunidad y no una fuente de ingresos para el gobierno. Debe notarse además que si el British Museum desea quedarse con un hallazgo aplicando sobre él el derecho de la Corona, normalmente paga su valor a quien lo ha encontrado, no ejerciendo sobre él ningún otro derecho.

La adecuación de la Ley del Treasure trove para otorgar una protección eficaz a los hallazgos arqueológicos está ampliamente contestada. Teniendo presente que el derecho es sólo sobre los elementos metálicos de oro y plata, su aplicación literal tiende a dividir el hallazgo entre los objetos realizados en metales nobles y el resto. Incluso se ha llegado a situaciones límite, como en el conocido caso AttorneyGeneral of the Duchy of Lancaster v. G.E. Overton (farms) Ltd., de 1980, en el que se realizaron análisis metalográficos para determinar si el contenido de las monedas era plata o una aleación en la que este metal era sólo una pequeña parte, y en razón de ello no estar sujeto el hallazgo al derecho de posesión de la Corona. Este ejemplo muestra cómo, a pesar de que la Common Law inglesa tiene muchos ejemplos de principios y conceptos que permiten adecuar usos originarios de ciertos derechos para afrontar las nuevas expectativas generadas por la sociedad moderna, en el caso de el treasure trove, los jueces no han sabido actualizarla a las exigencias de una protección de los hallazgos arqueológicos. En opinión de O'Keefe y Prott, a la vista de la inadecuación de la Ley sobre el Treasure trove, es una pena que el Reino Unido no haya seguido el ejemplo sueco de abolir la aplicación de esta ley a los restos arqueológicos; o bien, como se ha hecho en Dinamarca, ampliar su contenido para otorgar a los restos arqueológicos una conveniente cobertura jurídica (O'Keefe y Prott, 1984). Esta situación es particularmente preocupante por cuanto que el resto de la legislación sobre patrimonio histórico en el Reino Unido no ha conseguido crear un régimen jurídico específico para estas situaciones, al margen de esa norma. En resumen podría decirse que la fórmula de actuación en el Reino Unido para el caso de los hallazgos producidos por la actividad de detectoristas es más producto de una deficiencia legal que de una estrategia deliberada.

Por no extenderme más en esta divagación, sólo señalaré que para la normativa española, sin embargo, los bienes arqueológicos son de dominio público, situación a la que se ha llegado en ardua disputa con el derecho a la propiedad privada consagrado en el Código civil, que regulaba los supuestos de hallazgo de tesoros ocultos), proceso que ha corrido de la mano de una profunda revisión del derecho a la propiedad privada en aras a redimensionarlo desde una concepción que parte de su función social (Barrero Rodríguez, 1990 y Alegre Ávila, 1994).

Aunque en la práctica se han simultaneado las actuaciones legales para reprimir conductas expoliadoras con la compra más o menos subrepticia de hallazgos importantes, ciertamente la lucha contra el expolio se fortalecería si se siguiesen determinados comportamientos deontológicos entre los profesionales, y si las instituciones públicas y privadas implicadas siguiesen políticas coherentes con esta problemática, algo que no siempre sucede.

Por último, habría que hacer mención al importante esfuerzo normativo en materia de patrimonio histórico realizado a escala internacional, del Estado español y de las autonomías que lo componen. Aunque con algunas ausencias, se ha hecho común en todas las normas relacionadas con la protección del patrimonio histórico emanadas por estas instancias aludir al uso de detectores de metal. Su estudio resulta de interés para este trabajo, pero de momento sólo haré mención de las normas internacionales, dejando el resto para más adelante.

Así, en la Directiva 92I (198I), donde el Consejo de Europa muestra su preocupación por los efectos devastadores que está teniendo la amplia difusión y accesibilidad de los aparatos detectores de metal, señala en su recomendación |4.ii) que se considere la adopción por parte de los gobiernos, de las medidas necesarias para "instituir un sistema de licencias o registro de usuarios de detectores de metales".

Igualmente, la Convención de Malta (1992) en su artículo 3.iii) prevé, con el fin de preservar el patrimonio arqueológico y para garantizar el carácter científico de las actividades de investigación arqueológica, que cada país se comprometa a

\section{"Someter a autorización previa específica en los casos previstos por la legislación interna de cada Estado, el empleo de detectores de meta- les y de otros equipos de detección".}

Con independencia de que el tono "más débil del que a muchos les hubiese gustado ver", adoptado por esta Convención al tratar la cuestión de los detectores de metal, sea considerado una de las frustraciones más llamativas del documento por amplios sectores de profesionales (Cleere, 1998: 40 I), esta norma, como la anterior, indica explícitamente la conveniencia de que cada país establezca un tipo de licencias específicas para el uso de estos aparatos, como medio para controlar su afección al patrimonio arqueológico.

Volviendo al panorama del Estado español, quizás lo más llamativo de la eclosión de normas autonómicas en los dos o tres últimos años sea la falta de relación entre las nuevas obligaciones impuestas a las administraciones llamadas a ponerlas en práctica y los medios de que disponen para hacerlo. Se da la circunstancia de que, en muy pocas ocasiones, la aparición de una de estas leyes ha tenido como consecuencia la ampliación de los órganos administrativos directamente implicados en velar su cumplimiento. Carencia que habitualmente se encargan de recordar las recomendaciones internacionales y que, 
en este país, el propio legislador autónomo ha comenzado a poner de manifiesto en los preámbulos de algunas de estas normas sobre patrimonio cultural, consciente de que sin la necesaria implementación de medios, las leyes carecen de eficacia.

En fin, buena muestra de esta falta de contenidos concretos para acometer la lucha contra el expolio, tanto en experiencias como en indagaciones o reflexiones, se refleja en la escasez de trabajos publicados sobre este tema, aunque afortunadamente están empezando a ser más normales en los últimos años (Caballero Zoreda, 1982; Benítez de Lugo y Sánchez-Sierra, 1995; Querol y Martínez, 1996; Fernández Gómez, 1996, entre otros). También caben destacar el curso dedicado a la protección del patrimonio histórico especialmente dirigido a los cuerpos y fuerzas de seguridad del Estado, organizado por la Consejería de Cultura y Educación de la Región de Murcia en 1994 (Curso..., 1996) y las jornadas celebradas en Ávila, en 1997, producto de la colaboración entre la Junta de Castilla y León y la Guardia Civil (Jornadas..., 1998), que han dejado sendas publicaciones del máximo interés. No obstante, suele ser frecuente en muchos trabajos rellenar el espacio repitiendo una y otra vez las disposiciones legales vigentes sobre la protección del patrimonio histórico de carácter arqueológico, sin avanzar ni una sola propuesta sobre cómo paliar esta plaga o qué estrategia seguir para controlar determinados aspectos de la misma.

En resumen, estamos ante un campo de actuación que, a pesar de no ser rigurosamente nuevo, está prácticamente intacto incluso en el marco de actuación de las más altas instituciones, como corrobora el contenido dirigido hacia esta problemática concreta (el expolio de yacimientos arqueológicos) incluida en el "Decálogo para la lucha contra el expolio" elaborado por el Ministerio de Educación y Cultura, como conclusión de la reunión del Consejo de Patrimonio Histórico, celebrada en Alcalá de Henares, el 20 de febrero de 19983.

En este estado de cosas es utópico pensar que las administraciones culturales puedan ellas solas cumplir y hacer cumplir la legislación en esta materia. No obstante, algo se ha hecho y se está haciendo. En el resto del artículo avanzo un conjunto de propuestas, alguna de las cuales se están poniendo en práctica en Andalucía.

\section{Situación actual en Andalucía}

Producto de la poca dedicación dispensada al expolio arqueológico ocasionado por los detectores de metal, se han consolidado tópicos que enmascaran una realidad ciertamente más compleja, desconocida y amenazante, en relación con el uso de estos artefactos en Andalucía. Por ello conviene aproximarse a una panorámica de cómo ha cambiado esta cuestión en esta comunidad autónoma.
Según mi propia experiencia, iniciada a mitad de los ochenta como arqueólogo municipal en Écija (Sevilla), situada en el corazón de una de las zonas más activas en cuanto al comercio ilícito de piezas arqueológicas y al detectorismo, los hábitos expoliadores se han modificado en estos últimos años, de forma significativa.

La expansión del uso de detectores de metal, introducido en Andalucía por algunos estadounidenses de las bases de utilización conjunta de Rota (Cádiz) y Morón de la Frontera (Sevilla), coincidió con la roturación profunda mediante subsoladores de muchos campos de labor hasta entonces dedicados al cultivo del olivar, lo que facilitó hallazgos monetarios, y metálicos en general, ciertamente espectaculares, así como la entrada en un mercado consolidado, pero aún no saturado, de numerario en aceptable estado de conservación. Esto sentó las bases de un comercio rentable para quienes salían al campo a buscar monedas provistos de tales aparatos, que fueron rápidamente comercializados por la casa White's, radicada en Madrid.

Entre esta primera ola de buscadores se hallaban coleccionistas locales de corte erudito, como V. Durán, autor de un librito sobre la batalla de Munda basado en los hallazgos realizados por él mismo en los yacimientos del entorno de Écija (Durán Recio, 1984)4. Sus hipótesis y las evidencias que las sustentaban fueron bien recibidas en el ámbito universitario y, posteriormente, con la indispensable ayuda de un especialista en la época, reelaboró este trabajo en un tono más acorde con los usos científicos, depurado de toda la hojarasca erudita presente en la primera edición (Durán y Ferreiro, 1984).

Estos coleccionistas locales normalmente no solían vender piezas, salvo en casos de apuro económico severo. Pero pronto aparecerán junto a ellos aficionados, con niveles socioeconómicos más bajos, que no buscaban tanto la colección privada propia como el ánimo de lucro, abierto por las expectativas comerciales del negocio numismático.

Con el tiempo éstos terminarán por desplazar a aquéllos, que pasaron a ser meros espectadores del nuevo proceso que se estaba desarrollando. Efectivamente, la afluencia de anticuarios, coleccionistas e instituciones museísticas nacionales y extranjeros determinó la conversión de algunos de estos aficionados en intermediarios de un comercio ilegal de objetos antiguos que, como al apodado "El barbero de La Lantejuela" o al también barbero y propietario de bar denominado El Denario, de Écija (actualmente cerrado), les supuso un aceptable cambio a mejor en su nivel de vida. Las noticias de auténticos "pelotazos" animó a muchas personas a lanzarse al campo en busca de monedas y otros objetos metálicos antiguos. Obviamente, no puedo si quiera sugerir un número aproximado de cuántos empezaron a esta aventura; habitualmente se habla de miles de personas, asociándolo al paro agrícola. Bien, aunque sea indudable la relación entre ambos fenómenos, esas 
cifras publicadas frecuentemente en los medios de comunicación, me parecen una exageración. Como dato puedo señalar que a mitad de los ochenta en Écija había una docena corta de buscadores clandestinos en activo; me cuesta pensar que algunos años antes hubiese muchos más.

Esta edad de oro duró poco. La puesta en cultivo de esas tierras trajo aparejada el abono de las mismas con productos nitrogenados y fosfatados, que atacan el metal eliminando la pátina y corroyendo la pieza. Amén de ello, el mercado se saturó de piezas con la consiguiente bajada de los precios. De hecho, actualmente en los mercadillos callejeros la inmensa mayoría del numerario se vende al peso, razón por la cual las monedas no se limpian, ni clasifican y se exponen junto a otros objetos metálicos indeterminados.

Esta caída del mercado monetario ha inducido varios cambios para reajustar la actividad y el negocio al nuevo escenario. De una parte, ha animado la entrada de imitaciones, provocando incertidumbre en compradores poco expertos. Con bastante más repercusiones para nuestro interés, también fue la causa de la expansión de la actividad de los detectoristas a otras zonas de Andalucía como la vega antequerana, Ronda y las campiñas jiennenses, conformándose así un triángulo, circunscrito más o menos al valle del Guadalquivir, con inclusión de algunas vegas periféricas y zonas de costa, donde se produce la inmensa mayoría de esta modalidad de expolio arqueológico terrestre. Esta expansión de la actividad depredatoria ocasionó, a su vez, una doble reestructuración.

En primer lugar, se produce un nuevo reajuste: ante el deterioro irreversible de los objeto metálicos que no sean nobles, el expolio se extiende a objetos antiguos de todo tipo (esculturas de piedra, cerámica, vasos de vidrio, etcétera), que tienen igualmente cabida en el mundo del coleccionismo anticuarista. Para este menester se usan también los detectores de metal. La señal sonora emitida por estos aparatos se apaga cuando pasa sobre una estructura de fábrica, una diestra batida permite averiguar si la estructura enterrada se trata de una tumba o un muro de vivienda. Evidentemente para este tipo de trabajos un aparato medianamente bueno profundiza bastante más que cuando se trata de localizar una moneda, cuya masa es infinitamente menor. Una vez encontrada una tumba, en pocas horas, levantan una necrópolis entera, normalmente por la noche a la luz de los faros de un vehículo.

En segundo lugar, los buscadores pasarán de la actividad en solitario a organizarse en redes. Viajan en grupos de tres o cuatro personas, a medias en las ganancias. Cuando encuentran un buen hallazgo trabajan en turno rotativo. Además las máquinas usadas no tienen por qué pertenecerles, es frecuente el alquiler o la compra a plazos a los intermediarios, que reciben a cambio la exclusividad en manejar el producto de la rapiña, descontando el pago del pla- zo de la compra o del alquiler en especies. Al menos esto se deduce de algunas intervenciones del SEPRONA en que el propietario de las máquinas intervenidas no estaba entre los buscadores.

Sánchez Arroyo (1998: I43 s.) ha establecido una división similar a la que planteo aquí, pero no de carácter progresivo en el tiempo, sino como diversas facetas del modus operandi de los expoliadores, lo que también responde a la realidad. Es decir, todavía existen quienes salen al campo de forma individual para buscar monedas, como mero pasatiempo, pero indudablemente esta actividad va teniendo carácter residual con respecto de las redes organizadas. Por otra parte, hace veinte o veinticinco años no se conocían las redes organizadas, o no estaban dedicadas a esta modalidad de expolio. Por ello me parece determinante el factor temporal para comprender el fenómeno.

Podría resumir lo dicho hasta ahora, señalando que hoy día son menos quienes se dedican a salir al campo en busca de objetos metálicos o de otro tipo, e incluso ya no lo hacen con la frecuencia casi diaria de hace veinte o veinticinco años, pero a cambio quienes lo hacen están mejor organizados y tienen más movilidad, con lo cual el destrozo que producen es significativamente mayor.

Ya se ha mencionado la carencia de datos fiables sobre la magnitud del expolio, falta que da lugar a interpretaciones erróneas de los pocos manejables. Recientemente, la Dirección General de la Guardia Civil ha mostrado en diversas ocasiones (por ejemplo, en la reunión del Consejo de Patrimonio Histórico antes mencionada) una estadística sobre las actuaciones del SEPRONA en esta materia, en la que aparece Andalucía como la comunidad donde se produce aproximadamente el $70 \%$ del expolio dentro del Estado (Sánchez Arroyo, 1998: 142). Bien, ya se ha visto que Andalucía es un lugar preferente para la comisión de estos actos ilícitos, pero semejante desproporción es más que cuestionable. Para empezar la estadística enumera las denuncias realizadas por dicho servicio y no todos los expolios cometidos en los yacimientos; o sea que los datos expuestos dependen en alto grado de un cúmulo indefinido de variables humanas, imposibles de precisar y evaluar, como puede ser la mayor sensibilidad hacia esta problemática entre sus miembros. A este respecto, debe tomarse en cuenta que en fecha tan temprana como 1986, el Gobierno Civil de Sevilla emitía la circular número 2, de ese año, publicada en el Boletín Oficial de la Provincia, de 5 de mayo, en la que se advertía a los cuerpos y fuerzas de seguridad sobre

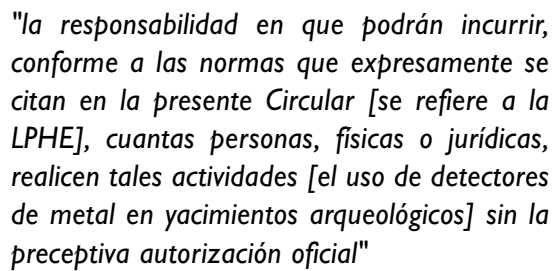

"la responsabilidad en que podrán incurrir, conforme a las normas que expresamente se citan en la presente Circular [se refiere a la LPHE], cuantas personas, fisicas o jurídicas, realicen tales actividades [el uso de detectores de metal en yacimientos arqueológicos] sin la preceptiva autorización oficial" 
y que con posterioridad se han dado cursos a los miembros de estos cuerpos, especialmente dirigidos al reconocimiento e identificación de material arqueológico.

Por otra parte, como norma, una estadística debería reflejar las diferencias entre una población de datos homogéneos y, en este caso, no lo son. Me explico. No parece coherente comparar comunidades uniprovinciales como Madrid o Murcia con otras pluriprovinciales, caso de Andalucía con una extensión de casi un tercio de toda la península ibérica, sin aplicar coeficientes de corrección; o, siguiendo esta misma línea, poner en el mismo saco zonas donde la inmensa mayoría del suelo rústico está arado -y por tanto la actividad del buscador es más factible- con otras, como Galicia, Asturias o Cantabria con una cobertura vegetal estable que dificulta el detectorismo. En conclusión, tomando en cuenta los datos brutos de denuncias del SEPRONA no cabe concluir la abismal distancia entre el expolio en Andalucía y el resto de comunidades del Estado español, como se ha hecho, sin que esta observación deba entenderse como negación de que efectivamente esta comunidad autónoma sufre un alto índice de expolio.

En todo caso, la respuesta de la Consejería de Cultura de la Junta de Andalucía ante las denuncias de actividades de los detectoristas, presentadas sobre todo por el SEPRONA y, en menor medida, por las policías locales y la policía judicial, también ha variado en el curso del tiempo, pero hasta la fecha se ha concentrado en la instrucción de expedientes sancionadores a quienes han sido sorprendidos con detectores de metal en yacimientos arqueológicos. En este proceso ha sido crucial la promulgación de la Ley I//99|, de 3 de julio, de Patrimonio Histórico de Andalucía (LPHA) 5 .

Quizás lo más interesante de la experiencia acumulada a lo largo de estos años haya sido el desarrollo interpretativo dado a los diversos preceptos sobre los que giran estos expedientes, por cuanto que este debate resulta perfectamente extrapolable a los nuevos marcos legales surgidos en las demás comunidades autónomas.

\section{La problemática en torno a la instrucción de expedientes sancionadores por uso de detectores de metal 6}

Inicialmente (esto es, desde la asunción de competencias por la Consejería de Cultura en 1984), la mayor parte de las denuncias fueron acumuladas sin mayor tramitación. Posteriormente, con la entrada en vigor de la LPHE se procedió a poner en marcha los expedientes que se habían acumulado. Se estudiaron y clasificaron las denuncias existentes con objeto de abrir, si procedía, expedientes sancionadores. Sin embargo, tanto las remitidas con anterioridad a la entrada en vigor de la LPHE, como la mayoría de las que podían sujetarse al amparo de sus determinaciones, se archivaron al entender que faltaba tipificación de las conductas de los buscadores de restos, por cuanto que si bien la LPHE condena el expolio, no dibuja nítidamente la conducta infractora.

Efectivamente, el artículo 4 LPHE habla de adopción de medidas contra el expolio, que después no tienen reflejo en el artículo 76 LPHE, donde se tipifican las conductas infractoras. En esta misma línea, se interpretaba por parte de los instructores de expedientes sancionadores, que lo dispuesto en los artículos 41.1 y 41.2 LPHE estaba destinado a someter a previa autorización determinadas prácticas: prospecciones y excavaciones (art. 42 LPHE) cuyo objetivo primario es la investigación, como se deduce de las definiciones que da el legislador de ambas técnicas, consecuentemente lo dispuesto en el artículo 76. I.f, en relación al 42.3 LPHE (esto es, la realización de estas actividades sin autorización), no es aplicable a la conducta de los detectores de metal, al no ser la investigación su objetivo, y su método no asimilable técnicamente a la prospección.

Igualmente han tenido incidencia negativa en la resolución de expedientes sancionadores administrativos el hecho de que los denunciantes hayan presentado, ante el órgano judicial correspondiente, denuncia de los hechos, ya que por vía penal el escaso valor de los objetos habitualmente encontrados en posesión de los usuarios de detectores de metal ha propiciado su sobreseimiento. Resuelto el caso penal con esa motivación, el expediente administrativo perdía efecto y contundencia. Además de ello, algunos instructores usaban los mismos argumentos esgrimidos por los jueces para resolver los expedientes administrativos, sobreseyéndolos. Con especial frecuencia se aducía el argumento de no estar los terrenos donde se encontraba el imputado de la acción declarados como zona arqueológica. Extremo éste que, afortunadamente, ha ido cambiando con el tiempo para adecuarse más a los preceptos de la legislación sobre patrimonio histórico.

La LPHA en su artículo I I 3.5 (que considera infracción menos grave "La utilización de aparatos destinados a la detección de restos arqueológicos sin contar con la autorización de la Administración de Cultura o sin cumplir los condicionamientos impuestos en la misma") intentaba cubrir la laguna de la tipificación, posibilitando la instrucción de expedientes sancionadores que, además, pasaron a ser competencia de las distintas delegaciones provinciales de la Consejería de Cultura.

Sin embargo, con ello no parecieron haberse solventado todos los obstáculos legales con que se han tropezado los instructores para poder probar que realmente los imputados cometieron la infracción. El punto clave, siguiendo en cierta medida lo expuesto sobre la LPHE, ha sido una cuestión de interpretación sobre la tipificación descrita en ese artículo.

Pronto prevaleció una interpretación para la que la expresión "destinados a" debía identificarse con el do- 
lo de la persona que usa el aparato, para buscar objetos arqueológicos. Se daba por supuesto que estos aparatos podían tener multitud de aplicaciones, estando sujetas sólo a previa autorización cuando se utilizasen para la detección de restos arqueológicos. De forma que para poder probar que realmente los imputados cometieron la infracción (esto es, que las personas sorprendidas con detectores de metal tenían la pretensión de encontrar restos), debía demostrarse su intencionalidad. Esta intencionalidad de buscar materiales arqueológicos solamente en contadas ocasiones podía ser objeto de prueba directa. Por esta causa muchos expedientes se habían sobreseído. Para superar este obstáculo se recurrió a la prueba indiciaria, y así poder imputar la infracción a los expedientados.

Para entender el valor de este tipo de pruebas debe acudirse a la propia jurisprudencia (por ejemplo, la STC 174/1985). Según esa sentencia, la prueba indiciaria ha de partir de unos hechos plenamente probados y llegarse, a través de un proceso mental razonado y acorde con las reglas del criterio humano, a considerar probados los hechos constitutivos de delito o infracción.

Aplicado al supuesto que comentamos, el hecho de encontrar un individuo en un lugar determinado provisto de un aparato detector de metales, por sí mismo, no sería constitutivo de infracción administrativa, sino simplemente un indicio del que pudiera llegar a concluirse la comisión de la infracción, basado en el nexo causal lógico existente entre el hecho probado y el que se trata de probar, esto es, entre encontrarse en un lugar provisto de un detector de metales y la utilización de estos aparatos con objeto de encontrar restos arqueológicos sin autorización, máxime si en el lugar de los hechos existe algún yacimiento arqueológico.

Por tanto, si como resultado de la investigación llevada a cabo en un expediente sancionador, resulta probado el hecho de encontrarse el sujeto en un yacimiento, o en el entorno del mismo, con un aparato detector de metales, a partir de ese hecho será lícito concluir que tal aparato estaba siendo utilizado para la búsqueda de restos arqueológicos, y por tanto será posible imputar la infracción tipificada en la LPHA, con independencia de que el yacimiento en cuestión se encuentre o no inscrito el Catálogo General del Patrimonio Histórico de Andalucía, o se haya declarado bien de interés cultural, puesto que el precepto mencionado no realiza distinción al respecto.

Cabe añadir que el Tribunal Superior de Justicia de Andalucía ha fallado favorablemente a las tesis de la Consejería de Cultura en los casos de recursos contra las resoluciones sancionadoras interpuestos por los afectados ante la Sala de lo contencioso administrativo, dando por válidas las deducciones realizadas por esta vía. Incluso, en una sentencia reciente del mismo Tribunal (enero del 2000), el magistrado ha dado un paso más, aunque dentro de esta misma línea argumental, preguntándose sobre el destino finalístico de la posesión de tales aparatos.
"La cuestión central del debate es la finalidad de la posesión del aparato. Con independencia de que en lugar más o menos próximo al de la denuncia existan yacimientos declarados o no, existe un indicio, a nuestro juicio muy poderoso. La posesión de un aparato detector de metales (y de restos arqueológicos) no tiene explicación en sí misma; es decir, nadie lleva un aparato de este tipo sin razón alguna; siempre, es lo lógico, se lleva para algo. $Y$ ese algo está constituido por las utilidades que el aparato en cuestión puede dar (...)".

Este razonamiento del magistrado, que le lleva a recabar de la parte actora una justificación verosímil de la tenencia y, ante su ausencia, a desestimar el recurso interpuesto y confirmar la sanción de la Consejería de Cultura, supone un innegable avance en comparación con los planteamientos que son habituales tanto entre jueces y magistrados, como entre los juristas de la propia administración.

Esta teoría sobre la necesidad de demostrar la intencionalidad de buscar objetos arqueológicos, que contraviene el tenor literal del mencionado artículo de la LPHA por cuanto que la concordancia gramatical de la expresión "destinados a" sólo puede ser con "aparatos", y no "uso", ha llevado la instrucción de los expedientes por un camino ciertamente tortuoso y difícil.

La insatisfacción de este sistema provocó que se sometiese a reflexión la cuestión de qué tipifica como conducta sancionable el artículo ||3.5 LPHA.

La tesis mantenida por A. Porras y J. M. Maldonado es que lo prohibido por el legislador andaluz es la actividad (esto es, el uso de un detector de metales), sin que tenga especial significación, a este respecto, la existencia del dolo específico de buscar restos arqueológicos.

Se asimilaría este precepto a otros en los que se prohibe la utilización de cierto tipo de artefactos sin entrar a considerar criterios de intencionalidad. Así, la Ley 4/1989, de 17 de marzo, de Protección de los Espacios Naturales y de la Fauna y Flora Silvestre, prohibe y sanciona la utilización de métodos masivos y no selectivos de caza, tales como trampas, cepos, lazos, etcétera, sin que haya en estas infracciones ninguna presunción de culpabilidad, pero ocurre que el aparato no discrimina si lo capturado (o detectado) integra o no el bien protegido. En nuestro caso, el detector registra lo mismo un objeto perteneciente al patrimonio arqueológico que otro metálico cualquiera; por tanto, para evitar la merma de bienes arqueológicos, se somete a previa autorización su uso y se sanciona a quien no cuente con ella o incumpla los condicionantes de la misma.

Esta interpretación se apoya también en la del artículo | | 2.4 LPHA, que califica de infracción grave "la realización de actividades arqueológicas sin cumplir los requisitos previstos en el artículo 52 de esta Ley 
o sin respetar los condicionantes impuestos en las autorizaciones administrativas". Por esta vía se sancionaría la realización de actividades arqueológicas sin autorización.

Prescindiendo de los elementos negativos que no afectan al núcleo de la cuestión debatida, para que una actividad sea sancionable ha de calificarse como arqueológica. Esta calificación no presentará problemas cuando esté hecha siguiendo la metodología impuesta por esa disciplina; pero es evidente que con mayor motivo deberá también sancionarse a quien realiza esas actividades de forma burda, sin método, con la intención de buscar restos arqueológicos. Es decir, que si quien está prospectando con un detector de metales lo hace con la intención de buscar restos arqueológicos, comete la infracción tipificada en el artículo I I 2.4 y no la del I I 3.5. Esto significa que si se acepta la tesis sostenida habitualmente, de precisarse una prueba de intencionalidad (búsqueda de restos arqueológicos) en la aplicación del artículo | |3.5, éste resultaría del todo inútil al estar la conducta ya tipificada en el II 2.4.

En definitiva, frente al artículo I I 2.4 LPHA en que la finalidad arqueológica se predica de la acción, en el artículo | | 3.5 LPHA ésta es predicable del aparato, con lo que la infracción se consuma con la mera aplicación del detector de metales, con independencia de la intención del autor. Así, el problema planteado por la aplicación del artículo | | 3.5 LPHA no es el de si el autor tenía o no la intención de buscar restos arqueológicos, sino el determinar cuáles sean esos aparatos destinados a la detección de restos arqueológicos, cuyo uso queda sujeto a previa autorización administrativa. Para el precepto antes señalado de la legislación medio ambiental, la administración ha solventado las dudas realizando una enumeración de los mismos en el RD 1095//989, de 8 de septiembre. No existe nada similar para la normativa de protección del patrimonio histórico. Este sería el colofón que completaría la normativa andaluza en este sentido.

Estas reflexiones fueron desestimadas porque se pensó que presentaban determinados problemas en orden a la seguridad jurídica de la actuación administrativa, concretada en este caso en la cuestión de la tipicidad de la conducta infractora.

La argumentación contraria a esta interpretación se sustenta sobre el hecho de que los detectores de metal no sólo sirven para anunciar la presencia de restos arqueológicos, sino que tienen otros muchas aplicaciones, con lo cual es preciso la concurrencia del instrumento adecuado y el lugar idóneo, esto es que se haga en un yacimiento arqueológico, para que exista -en razón de su competencia- causa para la intervención de la administración cultural. Desde este punto de vista, la LPHA sanciona la realización de la actividad arqueológica y no la mera intencionalidad, aunque para llegar a la convicción de que se ha consumado la actividad, mediante pruebas indiciarias, no sea ajena la intencionalidad del autor.
En lo referido a la duplicidad de artículos para la sanción de prospecciones arqueológicas con detectores de metal, se razona que la intención del legislador ha sido sacar de las sanciones consideradas graves ( I I 2.4 LPHA), el empleo de los detectores de metal, incluyéndolo, por tanto, en el I I3.5 LPHA. En aras de los principios de tipicidad y especificidad, éste sería el artículo de aplicación en estos supuestos y no el más genérico ( | | 2.4 LPHA).

No obstante, las reflexiones planteadas por A. Porras y J. M. Maldonado eran sumamente sugestivas $y$, por ello, a pesar de poco eco que han tenido en la práctica, se ha seguido insistiendo en este debate con la intención de aclarar algunos extremos ${ }^{7}$.

Así, parece determinante las posibilidades de un uso de estos aparatos distinto de la detección de objetos metálicos de carácter arqueológico. A este respecto, me gustaría apuntar unas observaciones.

Con independencia de las ocasionales aplicaciones en que puedan emplearse estos aparatos, la propaganda hecha por sus fabricantes de detectores de metal, aunque eviten mencionar términos directamente relacionados con el patrimonio histórico (antigüedades, etcétera) está indudablemente dirigida hacia esta actividad, disfrazada de

\section{"entretenido hobby de buscar toda clase de tesoros metálicos con un moderno detector de metales" (sacado del folleto publicitario de la marca COMPASS).}

Algunos aparatos poseen ingenios especiales para encontrar alteraciones del terreno de carácter arqueológico, como el modelo TM 808, de la casa White's, especialmente diseñado para la búsqueda de objetos metálicos grandes (pucheros llenos de monedas, balas de cañón, rifles, espadas...), que posee una función especial para

\section{"buscar cuevas, huecos, pozos y túneles; sitios populares para esconder objetos. Muchos objetos han sido escondidos en cuevas, o ente- rrados profundamente para evitar el hallazgo de su contenido".}

En ocasiones la relación con la práctica de excavaciones arqueológicas se plantea claramente, a pesar de no mencionarlas. Por ejemplo, en el relato de un experto detectorista estadounidense que acompaña la propaganda del modelo XLT de la marca Spectrum,

"Hace poco -cuenta E. Fedory- salimos a buscar reliquias y nos acercamos hasta un pueblo que había sido abandonado recientemente. Encontramos una serie de reliquias muy interesantes de finales del siglo XVIII y principios del $X I X$. Encontramos monedas de cobre y plata, cabezas de hacha y utensilios primitivos, municiones de mosquetes y antiguos misiles. Una excursión divertida con buenos resultados". 
O, como dice como reclamo un anuncio de venta por correo de detectores de metal,

\section{"A la caza del tesoro. Con este detector de metales puedes divertirte buscando monedas, joyas, antigüedades olvidadas,... Todo aquello escondido bajo la tierra..."}

En este mismo orden de cosas, los estatutos de las sociedades de detectoristas aficionados suelen contener cláusulas directamente relacionadas con la práctica arqueológica. Así, por ejemplo, la asociación Karmo, dedicada al fomento de la práctica del detectorismo, tiene entre sus estipulaciones para la admisión de un nuevo socio, el sometimiento del aspirante, por parte de la Junta Directiva, a un somero examen de "pericia arqueológica", con objeto de asegurar que el nuevo miembro "no cause destrozos innecesarios".

Más explícitos resultan los fines de la Asociación Corduba-Al Andalus de aficionados a la detección de metales y minerales, recogidos en sus estatutos. Figuran entre ellos

\section{"El desarrollo de una actividad cultural de tipo Arqueológico y Numismático, consistente en la búsqueda y detección, al aire libre, de Metales y Minerales en superficie, con detector de metales."}

"Organizar, explicar, debatir, asesorar y desarrollar la actividad de búsqueda, incluidos detectores, a sus Asociados."

Podría seguirse extrayendo ejemplos de propagandas de este tipo de aparatos o de los estatutos de asociaciones de aficionados al detectorismo, pero lo ya mencionado resulta suficiente para demostrar que los detectores de metal no son instrumentos inespecíficos, cuya simplicidad de funcionamiento les haga útiles para una amplia gama de actividades. Antes bien, se trata de artefactos complejos, cuyo diseño por sus fabricantes responde manifiestamente a la función de buscar objetos metálicos enterrados de carácter arqueológico en la inmensa mayoría de los casos. Y de ello son perfectamente conscientes los usuarios.

Aún cabría hacer una precisión más. La teórica aplicación de un aparato de estos a una actividad no relacionada directamente con la detección de restos arqueológicos carecería de peso como argumento para sostener su polivalencia, de igual forma que abrir la chapa de una botella de cerveza con un mechero no desvirtúa su función específica de producir una llama, para convertirlo en un abridor. Los detectores de metal están fabricados para advertir de la presencia de objetos metálicos enterrados, que tanto por su antigüedad, como por la metodología científica requerida para su localización, extracción y documentación deben considerarse como pertenecientes al patrimonio arqueológico.
No obstante, ciertamente existen aparatos de este tipo usados por empresas dedicadas al mantenimiento de redes de infraestructuras de saneamiento y conducción de agua, o bien por el ejército con fines militares. En estos supuestos, se emplean aparatos muy específicos, cuyo uso para estos fines carece de interés para la administración cultural.

Como consecuencia de este debate y dado que el expolio arqueológico, lejos de aminorar con el tiempo, ha cambiado sus formas de actuación pero sigue estando letalmente activo, parece haber cierto consenso en la Consejería de Cultura en aquilatar mejor el sentido del artículo I | 3.5 LPHA, mediante el desarrollo de un reglamento que regule las autorizaciones a las que hace mención ese precepto ${ }^{8}$.

Esto supondría establecer el procedimiento de autorización para el uso de aparatos detectores de metal, cuya venta y utilización -conviene no olvidarloes actualmente enteramente libre, como se concluye de un informe jurídico sobre la licitud de los detectores de metal y su aplicación, encargado por la Asociación Española de Detectoristas y publicado en el número 10 (1994) de El Buscador, tras consultar al Servicio de Explotación y Seguridad Minera del Ministerio de Industria y Energía, a la Dirección General de Seguridad del Estado y a la Jefatura de la $112^{\mathrm{a}}$ Comandancia de la Guardia Civil de Tres Cantos (Madrid).

Las claves de la propuesta de desarrollo mediante decreto, que actualmente está siendo sometida a debate, son las siguientes?:

a) Definir el concepto de utilización del aparato como tenencia o porteo del mismo en condiciones para su uso, esté o no en funcionamiento.

b) Establecer un procedimiento de autorización para quienes deseen usarlo, acreditando que se empleará para una finalidad y en un área en el que racionalmente no quepa duda alguna para la administración de que no es susceptible de causar daño al patrimonio arqueológico.

Esta limitación restringe, en la práctica, el uso del aparato detector a lugares, como la línea de playa, donde sea remota la aparición de restos arqueológicos, y sí sea posible encontrar objetos metálicos perdidos contemporáneamente, dando salida a un empleo de estos artefactos cada vez más habitual.

En caso de autorización, ésta sólo será válida para el área solicitada y durante el plazo de un mes. El procedimiento establece un tiempo de tres meses para que el órgano autorizante (la Dirección General de Bienes Culturales) resuelva, transcurrido el cual sin recaer resolución expresa, se entenderá desestimada la solicitud.

Por otra parte, en caso de ser estimada la solicitud, ésta debe portarse durante la utilización del aparato, a efectos de acreditar la licitud de su uso. Con 
ello, se facilitará enormemente la labor de control del SEPRONA u otros cuerpos de policía, que ejercen, entre otras funciones, esta tutela.

c) Se eximen de pedir autorización para el uso de detectores de metales a las empresas dedicadas a la construcción y mantenimiento de infraestructuras para el abastecimiento de agua y saneamiento, siempre que se empleen para esta finalidad, y a las Fuerzas Armadas para fines militares. En una disposición final se habilita al director general de Bienes Culturales para incorporar nuevos supuestos de exención de autorización, mediante resolución.

d) La propuesta dispone que el uso autorizado no exceptúa de los deberes que incumben a los halladores casuales de restos arqueológicos, en el caso de que éstos se produjeran, debiendo abstenerse de proseguir las tareas de localización y/o extracción, una vez detectado el primer resto o pieza arqueológica, considerándose en otro caso la actividad como expoliadora.

En fin, de aceptarse la propuesta en estos términos o en otros análogos, nos encontraríamos con un instrumento eficaz en la ardua lucha contra este tipo de expolio, que además solventaría el debate en torno a la instrucción de expedientes sancionadores abiertos por esta causa.

Con respecto de la situación en las demás comunidades autónomas, como se verá a continuación, el escenario dibujado para Andalucía referido a la propuesta de desarrollo reglamentario, supondría avanzar un paso más, por cuanto que en todas ellas aparece implícito un procedimiento de autorización, que no tiene por qué coincidir con el de las actividades arqueológicas.

\section{Análisis de las disposiciones sobre detectores de metales en otras comunidades autónomas}

La lucha contra el expolio provocado por los detectores de metal no ha sido privativa de Andalucía, en la mayoría de comunidades autónomas donde se ha legislado sobre patrimonio histórico, la actividad de los detectoristas ha estado presente en el ánimo de los legisladores.

Habitualmente estas disposiciones se han adoptado en el seno de leyes sobre patrimonio histórico, o cultural en general, pero también existen regulaciones expresamente dedicadas a esta problemática.

Caso paradigmático de esta última eventualidad es el Decreto 58/1994, de II de marzo, de la Consejería de Cultura y Turismo, de normas sobre prospecciones arqueológicas, utilización y publicidad de aparatos detectores de metal, de la Junta de Castilla y León. En la exposición de motivos se justifica la necesidad de esta norma en corregir la pérdida de yacimientos arqueológicos producto de la rebusca de materiales arqueológicos por parte de particulares, actividad agravada por el uso de detectores de metal. La estrategia seguida en el citado decreto ha sido asimilar la búsqueda de metales con detectores a las prospecciones arqueológicas (artículo 2.b.), actividad sujeta a la autorización de la Consejería, recordando la obligatoriedad de dar parte del cualquier hallazgo a la administración, sin perjuicio de las responsabilidades y sanciones a que diese lugar la práctica de tales actividades sin la debida autorización.

Como se ha señalado en otras ocasiones (Querol y Martínez, 1996: 25I), esta norma promete más de lo que se atreve a disponer. Realmente las prospecciones descritas en su artículo 2.b. lo son porque el Decreto lo dice, pero lo seguirían siendo aunque no lo dijese. Si se prueba que un sujeto examina un terreno con un detector de metales con la finalidad de buscar objetos susceptibles de ser estudiados arqueológicamente, tengan éstos valor crematístico o no, se trataría de un prospección arqueológica aunque el Decreto no lo mencionase, con lo cual supongo que para la instrucción de un expediente sancionador sería preciso demostrar que la persona imputada había realizado, estaba realizando, o tenía intención de realizar prospecciones arqueológicas. Esto será fácil si recogió algún hallazgo, pero de no darse esta circunstancia la demostración será más compleja, teniendo que recurrir a pruebas indiciarias para poder deducir la intencionalidad de la acción.

El Decreto 37/1997, de 19 de marzo, sobre prospecciones arqueológicas y utilización de aparatos detectores de metales en actividades que afecten al patrimonio histórico de la comunidad autónoma de Extremadura, es una copia casi literal del de CastillaLeón, con lo cual sería válido el comentario anterior. No obstante, la cuestión se complica un poco, pues la reciente Ley 2/1999, de 29 de marzo, de Patrimonio Histórico y Cultural de Extremadura (LPHCE) hace una distinción que, en principio, parece una reconsideración de lo decretado con anterioridad, pero que, en su actual redacción, considero bien una redundancia (algo a lo que tiene especial afecto el legislador extremeño habida cuenta del propio título de la Ley), o bien permisiva con el expolio, lo que sería aún peor.

Por un lado el artículo 50.a) LPHCE incluye, entre las modalidades de prospección a efectos de que se soliciten los correspondientes permisos, "aquellas técnicas de observación y reconocimiento del subsuelo mediante la aplicación de instrumentos geofísicos y electro magnéticos diseñados a tal efecto".

De otro lado, el artículo 56 LPHCE, específicamente dedicado a detectores de metal, prohibe la utilización de aparatos "que permitan la detección de objetos metálicos para la búsqueda de restos relacionados con la prehistoria, la historia, el arte, la arqueología, la paleontología y los componentes geológicos con ellas relacionados susceptibles de ser estudiados con metodología arqueológica, sin haber 
obtenido previamente una autorización administrativa que motivadamente justifique su empleo" (el subrayado es mío).

Entiendo que el legislador extremeño ha pretendido separar aquellas técnicas y aparatos geofísicos aplicables al estudios de las anomalías del subsuelo de origen antrópico, que son usadas por especialistas dentro de equipos amplios de investigación histórico-arqueológica y que está muy en boga actualmente debido a su carácter no destructivo, de la utilización de aparatos detectores de metal de carácter recreativo, al alcance de cualquier persona y que habitualmente se utilizan no para la investigación, sino para la mera localización de objetos metálicos antiguos. De esta forma, la LPHCE desharía lo dispuesto en el Decreto 37/1997, separando el empleo de los detectores de metal de la prospecciones arqueológicas.

Pero si esta no era la intención del legislador, no ha sabido plasmar lo que quería en la redacción del artículo 56 LPHCE. Este artículo incluye un elemento de intencionalidad en la prohibición, que como ya se ha dicho no siempre es de fácil constatación. Además, para colmo, se deja abierta la posibilidad a que se empleen estos aparatos para buscar restos arqueológicos con la correspondiente autorización administrativa, fuera del marco de las prospecciones arqueológicas, que ya están reguladas en el precitado artículo 50 LPHCE. Osea a que se pueda cometer expolio con autorización de la administración cultural.

Sería bueno que el prometido desarrollo reglamentario de esta ley aclarase estas dudas. De momento, la disposición derogatoria no enumera las disposiciones afectadas por ella, con lo cual está sujeto a interpretación si el Decreto 37/1997 sigue vigente o no. En mi opinión la filosofía de este decreto y la de la LPHCE son diferentes, con independencia de que la redacción del artículo 56 LPHCE pueda ser un auténtico disparate.

La Ley 4/1990, de 30 de mayo, del Patrimonio Histórico de Castilla-La Mancha, en su artículo 17 considera ilícita y sancionable la utilización de cualquier aparato cuyo funcionamiento esté encaminado a la obtención de restos arqueológicos, incluyendo este tipo de búsquedas dentro del concepto de prospecciones y excavaciones. Si bien esta norma no resuelve toda la problemática existente en torno al empleo de los detectores de metal, pero al dibujar la conducta infractora permite, por lo menos, aplicar las sanciones previstas en el artículo 76. I.f) LPHE.

La Ley $7 / 1990$, de 3 de julio, de Patrimonio Cultural Vasco presenta el indudable interés de haber dividido pormenorizadamente los tipos de prospecciones incluyendo entre las que no entrañan movimientos de tierra -y por tanto no están sujetas a la autorización previa de la administración cultural- las geofísicas (art. 45). Por otra parte, en el artículo 46 se declaran ilícitas las actuaciones arqueológicas sin autorización "incluso en aquellos casos que, no teniendo por fin el estudio del inte- rés arqueológico y paleontológico, sino cualquier otro ajeno a estas ciencias, quede afectado el patrimonio arqueológico y se demuestre el conocimiento de la existencia de éste por quien actuó". Afortunadamente el País Vasco cuenta con una protección natural, en forma de cubierta vegetal, que debe dificultar la actividad detectorista, porque no se lo ha puesto precisamente fácil el legislador a la administración. Si la diputación foral correspondiente desea imponer una multa a una persona sorprendida con un detector, aquí más que en ningún otro sitio deberá demostrarse de forma fehaciente el dolo de querer expoliar por parte de esa persona. Ignoro cómo se resuelven -o siquiera si se incoan- este tipo de expedientes, pero no sería de extrañar que en muchos casos no se concluyan por falta de medios para probar que quien usaba un detector era consciente de encontrarse en un yacimiento arqueológico.

El artículo 93.c) de la Ley 8/1995, de 30 de octubre, del Patrimonio Cultural de Galicia considera leve, grave o muy grave, en función del daño ocasionado, la utilización sin la debida autorización de "sistemas, técnicas y métodos de detección de bienes integrantes del patrimonio cultural...". Su regulación no está unida a la de las prospecciones u otro tipo de actividad arqueológica, por lo que la infracción se cometería con el mero hecho de usar tales sistemas, técnicas y métodos, sin necesidad de probar la intencionalidad de quien los usa, ni si son utilizados en yacimientos arqueológicos, pues el precepto no alude a tal circunstancia.

La Ley II//998, de 13 de octubre, de Patrimonio Cultural de Cantabria quiere apretar tanto la tuerca que complica enormemente su comprensión. Mientras que el artículo 76.3.b) define las prospecciones arqueológicas y engloba dentro de ellas la aplicación de técnicas especializadas para la teledetección, el artículo 78.2 prohibe el uso de detectores de metal y aparatos similares fuera las actuaciones legalmente autorizadas, esto es de las descritas en el artículo 76. Con ambos artículos resulta claro que aquí también se produciría la infracción con el simple uso no autorizado, sin entrar en mayores disquisiciones, pues previamente se han separado las actividades arqueológicas de la simple búsqueda de objetos arqueológicos con detectores de metal. Coherentemente con esta línea argumental, el artículo 132.b) considera la utilización no autorizada de sistemas, técnicas y métodos de detección de bienes integrantes del patrimonio cultural cántabro, tanto en el suelo, como en el subsuelo, en medio terrestre o acuático, como infracción leve, grave o muy grave, en razón del daño producido.

Con estos artículos quedaría perfectamente completo el cuadro dispositivo en lo tocante a detectores de metal. Pero al legislador cántabro debió parecerle poco y ha añadido otro artículo, presumo que perfectamente inútil, a no ser que en una corrección de errores se haya eliminado otro artículo. Me explico. El artículo |30.j) considera infracción grave la 
utilización de detectores de metal o aparatos de tecnología similar en actuaciones arqueológicas ilícitas o no expresamente autorizadas por la administración competente. Esta redundancia resulta más inexplicable si se tiene en cuenta que la realización de actividades arqueológicas sin autorización ya es tipificada como infracción grave en la letra i) del mismo artículo. La única explicación plausible que encuentro a este precepto es que la idea original del legislador fuese considerar el uso de detectores de metales y aparatos similares como agravante de una conducta subsumible en la tipificación de una infracción leve. Esta suposición estaría corroborada por el artículo 129.ñ) de esa ley que, con idéntica redacción a la del citado |30.i), estipula como infracción leve la realización de actividades arqueológicas ilícitas o las que se hagan contraviniendo los términos de la autorización. Si mi interpretación fuese correcta sobraría el artículo 130.i). Aunque puestos a eliminar artículos de esta norma, considero más oportuno suprimir justamente los otros dos: el 129.ñ) y el 130.j). En fin, a la ley cántabra le sobran artículos por todos lados.

Tampoco acierta mucho más la Ley 10/1998, de 9 de julio, de Patrimonio Histórico de la Comunidad de Madrid (LPHM), una de las más incomprensibles de todo el Estado. El artículo 44 de esta norma prohibe el uso de detectores de metales y otros instrumentos análogos "en el ámbito de los bienes integrantes del Patrimonio Histórico de la Comunidad de Madrid, salvo autorización...". Si por tal expresión se entendiese la definición contenida en el artículo I.3 de esa ley (entre ellos cualquier inmueble del que sea predicable algún tipo de interés arqueológico, los yacimientos y las zonas arqueológicas estén o no declarados) podría tener cierta escapatoria la redacción del artículo. Pero no es así. El artículo 60.3.f) tipifica claramente esta infracción como grave, siempre que el uso no autorizado de estos aparatos sea en "Zonas Arqueológicas o en el ámbito de inmuebles que hayan sido objeto de declaración como bien de interés cultural o incluidos en el Inventario". Fuera de esos lugares concretos no resulta preciso tener autorización para usar el detector de metales.

Imagino que para incoar un expediente sancionador a una persona sorprendida buscando restos con un detector en un yacimiento arqueológico no incluido en el Inventario ni declarado bien de interés cultural, será necesario probar que estaba desarrollando una actividad arqueológica no autorizada, con la finalidad de descubrir restos arqueológicos, pues el artículo 41.2 incluye esta posibilidad (la mera búsqueda de restos arqueológicos) y el artículo 60.5.b) tipifica esa conducta como grave o muy grave en función del daño. Pero, en este caso, no acierto a comprender por qué la conducta descrita en el artículo 44 LPHM en un yacimiento de singular importancia (y se supone que en razón de ello declarado bien de interés cultural o incluido en el Inventario) es una falta grave y fuera de ese ámbito esa misma conducta pueda ser muy grave en función del daño ocasionado.
Afortunadamente, los extremos incomprensibles en los que ha caído la LPHM, se han evitado en la Ley 12/1998 de 21 de diciembre del Patrimonio Histórico de las Islas Baleares. El artículo 25 de esta norma prohibe la utilización de detectores de metales en los bienes integrantes del patrimonio histórico de esta comunidad, con la salvedad de aquellos equipos de investigación que lo soliciten y obtengan permiso para ello. Como quiera que el artículo 102.1 I considera infracción grave el uso no autorizado de este tipo de aparatos en los bienes integrantes del patrimonio histórico de las Islas Baleares, ambos se remiten a lo especificado en el artículo 1.2, esto es, todos los bienes que revelen un interés cultural, en su sentido más amplio, para el archipiélago balear. Habida cuenta de que no es preciso que tales bienes estén declarados de interés cultural o recogidos en cualquiera de los catálogos e inventarios establecidos en esa norma, es plausible suponer, teniendo presente las características del patrimonio arqueológico, que dicha autorización sería virtualmente exigible en prácticamente todo el territorio porque resulta muy difícil eliminar a priori la presunción de existencia de restos arqueológicos en cualquier parte del territorio de esa comunidad, salvo en aquellos lugares en los que su formación geológica excluya todo tipo de actividad humana a lo largo de su historia, en cuyo caso carecería de sentido buscar restos arqueológicos con un detector de metales.

Algo similar se deduce del artículo 103.c) de la Ley 3/1999, de 3 de marzo, de Patrimonio Cultural Aragonés, que tipifica como infracción grave respecto de los bienes paleontológicos y arqueológicos, "la utilización clandestina de sistemas, técnicas y métodos de detección". Al referirse de forma genérica a bienes arqueológicos, opino que dada la amplitud de ese concepto queda claro, por las razones ya aducidas, que la infracción se consumaría con el uso no autorizado de estos aparatos, con independencia de la intencionalidad de quien lo usa o del lugar donde lo use, pues hay muy pocos lugares donde pueda presumirse que no podrán aparecer restos arqueológicos.

En resumen, prácticamente todas las normas buscan, siguiendo las directrices internacionales, someter a licencia previa el uso de aparatos detectores de metal. Pero a partir de esta premisa, la homogeneidad desaparece, a pesar de la evidente inspiración de unas en otras. Dejando aparte los casos en que una redacción desafortunada o la desconexión entre dos o más artículos de una misma norma conducen esta cuestión a situaciones absurdas o, cuando menos, de compleja interpretación, el resto de las leyes autonómicas podrían dividirse entre las que fundamentan el sometimiento a licencia el uso de estos artefactos incluyendo esta actividad entre las arqueológicas, y aquellas otras que son más proclives a prohibir la utilización de los mismos en la práctica totalidad del territorio de la comunidad, por la vía de la autorización excepcional.

Entre ambos sistemas, el primero me parece bastante más ineficaz, pues requiere probar la intencionali- 
dad de los imputados para poder aplicar una sanción, con su consiguiente dificultad. Por otra parte, la asociación de la búsqueda clandestina de objetos de valor crematístico a las actividades arqueológicas trastoca una línea, establecida en el derecho español desde la promulgación en 191। de la Ley de Excavaciones Arqueológicas, de cualificar científicamente este tipo de intervenciones sobre el patrimonio arqueológico para diferenciarlas precisamente de las expoliaciones. Separación que ha sido crecientemente más nítida conforme la arqueología ha ganado en rigor metodológico y epistemológico, hasta el punto de haberse convertido, la propia metodología arqueológica, en el criterio identificativo de este patrimonio especial.

Como se ha explicado páginas arriba, resulta necesario sancionar aquellas actividades que sin metodología arqueológica o con una de carácter burdo, afecten al patrimonio arqueológico, pero para ello no es necesario incluirlas en el mismo saco que las científicamente ortodoxas.

La otra estrategia parece más correcta, si bien a estos efectos puede devenir en un obstáculo haber restringido el ámbito de aplicación del precepto de solicitar autorización para el uso de estos aparatos a los bienes incluidos en le patrimonio histórico de la comunidad o al de los bienes arqueológicos.

\section{Otras actuaciones contra el expolio arqueológico}

El Plan General de Bienes Culturales de la Consejería de Cultura vigente entre 1989 y 1995 (Consejería de Cultura, 1993) no tomaba en consideración, de forma individualizada, el expolio arqueológico integrando las actuaciones contra el mismo dentro de la protección del patrimonio histórico, cuya principal preocupación era organizar e institucionalizar la elaboración de catálogos e inventarios de yacimientos arqueológicos, así como las declaraciones a efectos de la LPHE y LPHA. Esta labor devino en una de las principales actividades desplegadas por la Consejería, como muestran las memorias de gestión de los arqueólogos provinciales publicadas en los Anuarios Arqueológicos de Andalucía.

No obstante, a su amparo se desarrollaron todas las actuaciones sancionadoras descritas anteriormente, se impartieron en prácticamente todas las provincias cursos divulgativos y de información a los cuerpos y fuerzas de seguridad -aunque no con la periodicidad requerida por la frecuente renovación de la plantilla de esos cuerpos-, y apareció la LPHA, que presta especial atención a esta problemática.

El nuevo Plan General de Bienes Culturales 19962000, sí ha considerado conveniente incluir, entre las líneas de actuación del programa de protección, una específicamente dirigida a la lucha contra el expolio de yacimientos arqueológicos. Sus objetivos se cifran en varios campos, desarrolados mediante proyectos concretos (Consejería de Cultura, 1997: 126).

Las medidas y actuaciones dirigidas a la coordinación con las demás instituciones y organismos implicados en la lucha contra el expolio no requieren mayor explicación, pues se han convertido en una práctica (o deseo) habitual en la mayoría de las comunidades autónomas. Otro tanto puede decirse de aquéllas destinadas al perfeccionamiento de la capacitación de los agentes de la policía judicial y del SEPRONA para esta tarea. Sobre la intención de regular la autorización de los detectores de metal, ya se ha visto por dónde se mueve el debate jurídico, aunque deba reconocerse que éste no partió como desarrollo del Plan General, sino desde la experiencia en la instrucción de expedientes sancionadores. Sí debería, sin embargo, explicarse la medida dirigida a la protección física de los yacimientos arqueológicos con antecedentes de expolio significativo, consistente en el "sembrado de virutas metálicas", por cuanto que pueda parecer anecdótico o no sea fácil de comprender 10 .

La experiencia demuestra que la protección física estática de los yacimientos, fundamentalmente el vallado, sólo es relativamente eficaz en aquellos donde a esto se suma la vigilancia activa, algo que sólo es posible en un corto número de yacimientos. En el resto, la protección física destinada a desalentar a los detectoristas aficionados debe ser más imaginativa.

Así las cosas, contrariamente a lo que parece, la propuesta reflejada en el Plan General de Bienes Culturales no está dirigida a dificultar la detección de metales, ya que normalmente estos aparatos están provistos de discriminadores que evitan ese tipo de interferencias, sino que su objetivo es impedir el hallazgo de tumbas. Como ya se dijo anteriormente, para este menester también se usan los detectores de metal, siendo así que los nuevos modelos, como el TM 808, permite profundizar hasta 2'5 m, para detectar objetos con una capacidad de 15 litros. A este respecto se ha observado que un nuevo tipo de abono de tipo compost sacado de reciclar basuras urbanas, rico en detritos metálicos, dificulta la detección no de metales, sino del material constructivo empleado en las estructuras funerarias. Efectivamente, el empleo sistemático del discriminador, a que obliga la presencia de pequeños fragmentos metálicos de tamaño y naturaleza diversa, amortigua el tono base del aparato hasta una frecuencia que apenas permite el contraste.

Esta práctica ya ha sido aplicada en diversos lugares de Andalucía. En Galera (Granada), por ejemplo, profesores de EGB organizaron patrullas de estudiantes que durante los fines de semana esparcían chapas de botellas, recolectadas en los bares, en los yacimientos arqueológicos con el propósito de intentar despistar a los detectoristas. También se ha probado con fragmentos de imanes, que bloquean las agujas de los aparatos menos sofisticados. Iniciativas similares han tenido lugar en Osuna (Sevilla), sometidas a expolios intensivos, con notable éxito. 
El propósito del Plan General era precisamente recoger lo positivo de estas iniciativas y encauzarlas a través de campañas que involucrasen a la población escolar para que, además, sirviesen como medio de sensibilizarlos sobre la pérdida irreparable derivada de la acción de los expoliadores.

Por razones que no hacen al caso, el Plan General de Bienes Culturales 1996-2000 ha tenido una tramitación excesivamente larga, con lo cual muy poco de lo dispuesto en él ha podido activarse. Entre ello no está esta iniciativa. No obstante, la lucha contra el expolio es una línea de actuación de la administración que trasciende los periodos de vigencia de los planes, por lo que siempre se estaría a tiempo de avanzar por estos caminos, como programas autónomos de los planes donde se alumbraron, sin necesidad de esperar la luz verde de su aprobación definitiva.

En esta misma situación de falta de impulso para su materialización, se encuentran determinadas disposiciones recogidas en la legislación sobre patrimonio histórico, cuya puesta en práctica ayudaría bastante en la persecución del comercio ilícito. Es el caso de la obligación de las personas y entidades dedicadas al comercio de bienes muebles de carácter cultural (anticuarios, marchantes y casas de subastas, entre otros), de llevar un libro de registro en el que anotar todas las transacciones de bienes inscritos en el Catálogo General del Patrimonio Histórico Andaluz y, en todo caso, superiores a cincuenta años de antigüedad. Este libro de registro habría de seguir un modelo oficial aprobado por la Consejería de Cultura (artículos 46 LPHA y 67 a 7 I del Reglamento de Protección y Fomento del Patrimonio Histórico de Andalucía de 1995), que aún no se ha publicado.

\section{La difusión del patrimonio arqueológico como instrumento de prevención}

Existe una lógica coincidencia entre quienes se enfrentan a la cuestión del expolio en abogar por medios educativos y de sensibilización social como inversión más segura, a medio y corto plazo, para erradicar en gran medida tanto las propias conductas expoliadoras como la indiferencia social hacia la sangría del patrimonio arqueológico que conlleva.

La Recomendación 921 del Consejo de Europa dice en su sexto considerando "Alegrándose del interés del público en la arqueología, pero deseando fomentar el interés a través de un grado de involucración superior de un público responsable en arqueología y una mejor apreciación de las evidencias que la investigación arqueológica puede revelar", para proponer seguidamente entre otras cosas que se lance una campaña informativa sobre arqueología coordinada por el Consejo de Europa, dirigida al público en general, a los gobiernos y a los comerciantes de detectores de metales y antigüedades, así como que se apoye la inclusión de una Introducción a la Arqueología en la educación escolar, como parte de los estudios de historia, para así fomentar una actitud más responsable hacia los vestigios del pasado.

Por su parte, la Convención de Malta prevé el compromiso de los miembros firmantes de la misma para emprender una acción educativa destinada a despertar y desarrollar en la opinión pública una conciencia sobre el valor del patrimonio arqueológico para el conocimiento del pasado, y sobre los peligros que amenazan a este patrimonio, así como para promover el acceso del público a los elementos principales de su patrimonio arqueológico, sobre todo a los yacimientos arqueológicos, y a apoyar la exposición al público de los bienes arqueológicos seleccionados.

Como han expresado con acierto M. A. Querol y B. Martínez (1996: 252) "la verdadera lucha contra estas intervenciones clandestinas, en algunas regiones mucho mayores en número e incidencia que las autorizadas, pasa a la fuerza por una inversión a largo plazo ante la que las Administraciones competentes parecen remisas: la modificación de los curricula educativos con la introducción de nociones sobre la existencia, el verdadero valor, el posible tratamiento y el significado del patrimonio arqueológico".

No obstante, a pesar de todas estas advertencias y recomendaciones, no siempre existe en el ámbito de la difusión una postura coherente que secunde la labor de lucha contra el expolio desarrollada por la propia administración. Es como si lo hecho con una mano, a veces se deshiciese con la otra.

Muchísimos museos arqueológicos todavía están aferrados a un discurso centrado en las piezas, siguiendo un paradigma cientíico desfasado, que apenas da importancia al relato histórico contextualizador de los objetos comunes y artísticos, y a los procesos de conocimiento y cambio social, prefiriendo llamar la atención del público sobre piezas insólitas por su rareza o calidad artística. Lo peor de este discurso, que algunos denominan "arqueográfico" (Alcina, 1975), es que retroalimenta el gusto anticuarista por atesorar bienes poco frecuentes, ya sea en colecciones públicas o privadas (Ruiz, Molinos y Hornos, 1986).

Los efectos de la obsolescencia en la presentación de las colecciones de muchas instituciones museísticas se dejan rápidamente sentir en los nuevos museos locales que han ido surgiendo en los últimos años, al seguir los patrones de los provinciales, de mostrar piezas bellas esperando que éstas por sí mismas transmitan el mensaje que quienes las han situado no sabían construir. En los museos locales, la situación en doblemente negativa: a la sustitución del relato por el objeto se une, además, que estas instituciones suelen partir de colecciones fundacionales constituidas por materiales expoliados por vecinos que, mediante la donación o depósito de todo lo que no pueden vender, pasan a ser considerados como benefactores de la cultura local. 
Caso paradigmático ha sido el Museo de Historia Local de Écija (Sevilla). En su primer montaje despreciaba años de investigación histórica y arqueológica realizados en esta ciudad, en aras de mostrar un batiburrillo de objetos procedentes de expolios, pero que a diferencia de los recogidos en las excavaciones urbanas estaban enteros o eran raros, con la obtusa idea de servir de reclamo a paisanos y turistas (Rodríguez Temiño, 2000). Afortunadamente, a raíz de las críticas recibidas las autoridades municipales decidieron cambiar de estrategia y, en lugar de despilfarrar el presupuesto comprando colecciones particulares, se encargó a una empresa de arqueólogos profesionales la elaboración de un proyecto museológico nuevo, que parece haber corregido -al menos en parte- los dislates iniciales.

Por otra parte, las exposiciones temporales, actividad actualmente privilegiada en el campo de la difusión, debería tener una incidencia enorme en este proceso educativo y de concienciación, habida cuenta del éxito de público que concitan. Desgraciadamente, las dedicadas al patrimonio arqueológico frecuentemente sólo innovan en los recursos museográficos (esto es, en la presentación de las piezas), pero el discurso positivista en torno al objeto sigue siendo igual de rancio que siempre. Serían muchos los ejemplos que podrían aducirse a este respecto, pero por su especial énfasis en el expolio y para ilustrar las dos caras de la moneda, me ceñiré a dos recientes, que además fueron casi simultáneas aunque en ciudades distintas (Rodríguez Temiño, 1998).

En Sevilla (1998) se mostraba una exposición titulada Egipto milenario. Vida cotidiana en la época de los faraones, en la que pretendía, como su nombre indica, dar una visión sobre aspectos menos conocidos del antiguo Egipto, a través de una colección de objetos artesanales de uso habitual en ese tiempo procedentes de los fondos del Roemer und Pelizaeus Museum de Hildesheim (Alemania).

A pesar de ser una muestra de formato reducido, la puesta en escena era realmente exquisita. Un vídeo recibía a los visitante, vitrinas diseñadas especialmente resaltaban los efectos de luz sobre las piezas, etcétera. Sin embargo, esta es la típica exposición en que las piezas arqueológicas son un mero adorno de un discurso basado fundamentalmente en el conocimiento transmitido por los textos. La arqueología se retrotrae, contrariamente a lo que sugería el vídeo inicial, a la época en que se identificaba con la anticuaria, es decir, con el coleccionismo de objetos. La organización del ejército o el panteón de dioses egipcios-por poner dos de los temas tratados- se ilustraban con determinados artefactos, pero la información dada de ellos no se deducían de los objetos mostrados; incluso se habían omitido poner de manifiesto las relaciones entre las distintas facetas sociales y económicas de esa sociedad, proceso lógico cuando se pretende dar una idea global de cualquier comunidad humana, y argumento imprescindible en la investigación arqueológica.
Supongo que no será baladí, para entender esta aproximación a la función de la arqueología en el conocimiento sobre las sociedades antiguas, saber que la totalidad de las piezas mostradas son producto de expolio, aunque sea del siglo pasado, como demuestra la ignorancia de los lugares de procedencia de las piezas. Quizás lo más lamentable de este caso es que, por ningún medio, se hiciese mención de esta circunstancia, con lo cual la exposición perdía un plus de interés al haber podido entroncar con una problemática actual, y unir a la información de los objetos su propio discurso como colección.

Por contra, por Granada y Jaén se exponía la muestra Hace 4000 años..., basada en el proyecto de investigación de dos poblados prehistóricos de ambas provincias desarrollado por la Universidad de Granada. En ella, la arqueología se expone desde una perspectiva científica, como una disciplina destinada a reintegrarnos el conocimiento de nuestro pasado a través del estudio de la cultura material y la evidencia medio ambiental. Dedicaba, por tanto, especial relevancia a la metodología usada en el registro arqueológico y su conversión en historia, a la vez que daba información sobre los modos de vida de las sociedades analizadas; discursos apoyados con la documentación gráfica y los objetos materiales que componen la propia exposición.

Aunque no se aludía explícitamente, se hacía patente la distinción entre registro de la evidencia arqueológica y la posterior elaboración de la memoria colectiva, que es historia e interpretación a partir de ella, y depredación de un yacimiento mediante la rebusca de objetos en la que todo este caudal informativo se pierde irremisiblemente.

Resulta necesario que las administraciones culturales potencien este tipo de exposiciones, e incluso diseñen otras especialmente dedicadas a sensibilizar sobre los efectos producidos por el expolio y el contrabando de bienes culturales. La muestra denominada Procedencia desconocida, presentada en Kassel en 1995, precedida de bastante éxito durante una gira previa por ciudades alemanas y suizas (Graepler, 1995); o Italia con su campaña Stop al vandalismo gráfico, iniciativa dirigida hacia los más jóvenes para concienciarlos sobre los efectos nocivos de los grafitos en monumentos, ofrecen un buen ejemplo a seguir.

Por último, quisiera acabar con una nota optimista. Actualmente se está consolidando un movimiento de concienciación internacional, auspiciado por los más importantes museos de los países tradicionalmente compradores, cuya acta de nacimiento fue la Declaración de Berlín, aprobada en 1988 por iniciativa especial del profesor Heilmeyer, director del Antikenmuseum de Berlín (Pallottino, 1992). En esta declaración las grandes instituciones museísticas reconocen la prioridad del valor científico de objetos arqueológicos y adquieren el compromiso de rechazar cualquier pieza de la que se desconozca la procedencia, como contribución en la lucha para frenar esta lacra. 
Estas declaraciones no se han quedado en píos propósitos y aunque el comercio internacional de objetos expoliados sigue existiendo, a pesar de las normas internacionales que lo persiguen, muchos de los grandes museos occidentales, se abstienen de comprar piezas cuyo origen es desconocido. En coherencia con la suscripción de esta declaración y en aplicación de la normativa internacional sobre comercio ilícito de bienes culturales, estos centros sue- len poner en conocimiento de las autoridades nacionales competentes las ofertas de venta de bienes extraídos y comercializados por vías clandestinas, que les hacen.

Obviamente, éstos no pueden ser los únicos recursos, pero su consolidación reforzará las normativas represoras del expolio y el comercio ilícito de antigüedades.
ALCINA FRANCH, J. ( 1975). "La arqueología antropológica en España: situación y perspectivas", I Reunión de Antropólogos Españoles (Sevilla, 1973), Sevilla: 47-62.

ALEGRE ÁVILA, J. M. (1994). Evolución y régimen jurídico del Patrimonio Histórico, Ministerio de Cultura, Madrid, (2 vols.).

ALONSO IBÁÑEZ, M. R. (1992). El patrimonio histórico. Destino público y valor cultural, Civitas, Madrid.

BARRERO RODRÍGUEZ, C. (1990). La ordenación jurídica del Patrimonio Histórico, Civitas, Madrid.

BENÍTEZ DE LUGO ENRICH, L. y A. E. SÁNCHEZ-SIERRA (1995). "El furtivismo arqueológico. Consideraciones legales y científicas sobre los hallazgos arqueológicos", Boletín Informativo, 12, Instituto Andaluz de Patrimonio Histórico: 38-43.

CABALLERO ZOREDA, L. ( 1982). "Los detectores de metal", Revista de Arqueología, 17: 28 y s.

CLEERE, H. (1998). "Managing the archaeological heritage", Antiquity, 67: 400-402.

CONSEJERÍA DE CULTURA, JUNTA DE ANDALUCÍA (1993). Plan General de Bienes Culturales, Sevilla.

- (1997). Plan General de Bienes Culturales de Andalucía.

1996-2000, Sevilla.

Curso: Protección del patrimonio arqueológico, dirigido a los cuerpos y fuerzas de seguridad del Estado, (Murcia, 1994) (1996). Región de Murcia, Murcia.

DURÁN RECIO, V. (1984). La batalla de Munda, Córdoba.

DURÁN RECIO, V. y M. FERREIRO LÓPEZ (1984). "Acerca del lugar donde se dio la batalla de Munda", Habis, 15: 229-236.

Egipto Milenario. Vida cotidiana en la época de los faraones (1998). Catálogo de la exposición, Fundación "La Caixa", Barcelona.

ENGLISH HERITAGE (199I). Exploring our Past. Strategies for the Archaeology of England, English Heritage, Londres.

FERNÁNDEZ GÓMEZ, F. (1996). "De excavaciones clandestinas, mercado de antigüedades y publicación de 'hallazgos'", en M. A. Querol y T. Chapa (eds.), Homenaje al Profesor Manuel Fernández-Miranda, Complutum Extra, 6 (II): 283-294.
GRAEPLER, D. (1995). "Fundort unbekannt! Eine Wanderausstellung über Raubgrabungen", Antike Welt 1995-3: 221-223.

Hace 4000 años... Vida y muerte en dos poblados de la alta Andalucía (1997). Catálogo de la Exposición, Consejería de Cultura de la Junta de Andalucía, Fundación Caja Granada y Universidad de Granada, Granada.

INIESTA SANMARTíN, Á. (1996). "Los daños sobre el patrimonio arqueológico: actividades que los generan y actuación policial sobre el terreno", en Curso: Protección del patrimonio arqueológico, dirigido a los cuerpos y fuerzas de seguridad del Estado, (Murcia, 1994), Región de Murcia, Murcia: 65-100.

O'KEEFE, P. J. y L. V. PROTT (1984). Law and the cultural heritage. Discovery and excavation, vol. I, Professional Books Limited, Oxford.

PALlOTTINO, M. (1992). "Beni archeologici in Europa (Tavola rotonda, intervento conclusivo). Risoluzioni", Eutopia, I: I |3-1 I7.

Protección del patrimonio histórico. La Guardia Civil y la conservación de los bienes culturales, (Ávila, 1997) (1998). Junta de Castilla y León y Guardia Civil, Valladolid.

QUEROL, M. A. y B. MARTíNEZ DÍAZ (1996). La gestión del Patrimonio Arqueológico en España, Alianza Editorial, Madrid.

RODRÍGUEZ TEMIÑ̃O, I. (1998). "Exposiciones de arqueología y expolio", El Correo de Andalucía de 24 de febrero.

- 2000. "La gestión del patrimonio arqueológico en Écija", V Congreso de Historia de Écija (Écija, 1998), Ayuntamiento de Écija, Écija: 189-203.

RUIZ RODRÍGUEZ, A.; M. MOLINOS MOLINOS y F. HORNOS MATA (1986). Arqueología en Jaén (Reflexiones desde un proyecto arqueológico no inocente), Diputación Provincial de Jaén, Jaén.

SÁNCHEZ ARROYO, J. A. (1998). "Expolio Arqueológico", Protección del patrimonio histórico. La Guardia Civil y la conservación de los bienes culturales, (Ávila, 1997), Junta de Castilla y León y Guardia Civil, Valladolid: 137-146. 
I. A este respecto debería tenerse presente que el patrimonio arqueológico, como sostiene M. R. Alonso (1992), aparece perfectamente identificado e individualizado en la el artículo 40 LPHE, de forma que cualquier reconocimiento oficial, no necesariamente expresado a través de un procedimiento administrativo ad hoc, tiene validez para significar la pertenencia de un yacimiento al patrimonio histórico español.

2. En España fue casi nulo el eco que tuvo en medio oficiales y profesionales la recomendación 921 (1981) de la Asamblea parlamentaria del Consejo de Europa, relativa a detectores de metal y arqueología. Posiblemente la única excepción fue $L$. Caballero Zoreda, quien dedicó un breve artículo a comentarla (Caballero Zoreda, 1982)

3. "Se estudiarán medidas concretas y específicas para evitar el expolio en yacimientos arqueológicos tanto terrestres como subacuáticos", Hispania Nostra, 7I/72, abril de 1998, p. 16.

4. Especialmente interesante era un botón de plata con las iniciales A. Varo, general pompeyano muerto en esa batalla, y que, tras ser comprado por el cabildo ecijano a finales de los ochenta -al igual que el resto de la colección perteneciente al Sr. Durán-, se encuentra en paradero desconocido, sin que nadie sepa dar razón de qué ha pasado con esa pieza.

5. En números absolutos, el monto de expedientes tramitados en Andalucía supera con creces al de las demás comunidades autónomas, según comunicación oral de A. Yáñez, quien está actualmente ultimando un estudio sobre expedientes sancionadores por esta causa en el Estado español entre 1985 y 1995.

6. Estos comentarios han sido mantenidos por A. Porras Posadas, secretario de la Delegación Provincial de Cultura en Córdoba, J. M. Maldonado, técnico de la misma Delegación Provincial y L. Jover Oliver, jefe del Servicio de Asuntos Jurídicos de la Consejería de Cultura. Agradezco que me hayan dejado citar las conclusiones de sus informes.

7. Afortunadamente, como muestra la sentencia del Tribunal Superior de Justicia de Andalucía antes comentada, parece que la jurisdicción de lo contencioso administrativo en Andalucía, va llegando a planteamientos muy similares a los mantenidos por estos autores.

8. Con independencia de que también se estudie la modificación de la LPHA en éste y otros aspectos.

9. La propuesta ha sido redactada por F. Valverde, secretario de la Delegación Provincial de Cultura en Cádiz.

10. "Actuar con los colegios en la protección física de yacimientos sembrándolos de virutas metálicas, no discriminadas por los detectores de metal". 